\title{
A obrigatoriedade de matrícula na pré-escola no campo: um debate necessário
}

\author{
Simone Santos de Albuquerque \\ Crisliane Boito \\ Universidade Federal do Rio Grande do Sul
}

\section{Resumo}

Este artigo resulta de uma pesquisa qualitativa de cunho etnográfico, realizada no assentamento de Trabalhadores Rurais Sem-Terra - Integração Gaúcha/IRGA, localizado em Eldorado do Sul/RS. O estudo insere-se no campo das Políticas Públicas para Educação Infantil e busca conhecer as perspectivas das famílias do campo em relação à Lei 12.796/13, que regulamenta a obrigatoriedade de matrícula de crianças a partir de quatro anos na educação infantil. O foco da análise deu-se, principalmente, por meio de entrevistas com seis famílias, que apontaram o desejo de que as crianças participem da vida familiar no campo e de que a matrícula na educação infantil seja opção da família.

Palavras-chave: Obrigatoriedade. Educação infantil. Famílias assentadas. 


\section{The kindergarten enrollment in the field as mandatory: a necessary debate}

This paper is the result of an ethnographic qualitative research made in the Landless Rural Workers settlement - Rural Integration (Integração Rural)/IRGA, at Eldorado do Sul/RS. The study is inserted in the Public Policies for Children Education and aims to know the perspectives of field families considering the Law 12.796/13, which regulates the enrollment of children of four years old or older at a children educational institution as mandatory. The focus of this analysis were the interviews made with six families, which pointed the wish of the children participation in the family life, in the field and the enrollment at an educational institution to be optional.

Keywords: Mandatory. Children Education. Settled Families.

\section{La obligatoriedad de La matricula em La pré- escuela del campo: um debate necesario}

El artículo es el resultado de investigar cualitativa y etnográficamente el assentamiento de los Trabalhadores Sem Terra - Integração Gaúcha / IRGA, ubicados em Eldorado do Sul/RS. El presente estudio forma parte de las Políticas Públicas para la Educación Infantil; y pretende conocer las perspectivas de las familias rurales, en relación a La Ley 12.796/13, la cual se encarga de regular la inscripción obligatoria de los niños de cuatro años en la Educación Infantil. A través de este análisis determinaremos el deseo de los niños a una participación en una vida familiar en entorno rurales, y que la matrícula em Educación Infantil sea uma opción por y para las famílias.

Palabras clave: Obligatoriedad. Educación infantil. Assentamientos de Familias. 
Todo trabalho de pesquisa possui uma implicação, que pode ser referida pela temática, pelo referencial teórico, pela militância; enfim, são diferentes as razões que se apresentaram em nossa trajetória recente de pesquisa, a qual tem suscitado diferentes estudos, investigações e problematizações acerca da temática que envolve a educação infantil, a educação infantil do campo e a questão da obrigatoriedade de matrícula na pré-escola. A tessitura deste artigo está profundamente relacionada às nossas vivências como pesquisadoras, com experiências que temos vivenciado e com a trajetória que temos construído em torno do tema.

A educação infantil é a primeira etapa da educação básica, é direito das crianças garantido desde a Constituição da República Federativa do Brasil de 1988. A Lei de Diretrizes e Bases da Educação Nacional (LDBEN), em seu art. $4^{\circ}$, estabelece que é dever do Estado garantir educação infantil a crianças de até cinco anos de idade.

Nas últimas décadas, vivenciamos diferentes movimentos para o reconhecimento da educação infantil como primeira etapa da educação básica, como o Movimento "Fraldas Pintadas", instaurado pelo Movimento Interfóruns de Educação Infantil do Brasil (MIEIB), para que a creche fosse incorporada no Fundo de Manutenção e Desenvolvimento da Educação Básica e de Valorização dos Profissionais da Educação (Fundeb). O reconhecimento da educação infantil é pauta importante no sistema educacional brasileiro, mas é preciso ter cautela ao reconhecer as novas tensões que se estabelecem ao integrá-la.

Já a educação do campo é uma luta histórica dos movimentos sociais que reivindicam uma educação no campo para os sujeitos que ali vivem. Articular educação infantil e educação do campo tem sido um exercício de diálogo e pesquisa, instaurado na troca entre os movimentos sociais vinculados à educação infantil e à educação do campo, e, também, entre universidades brasileiras que têm se dedicado à pesquisa ${ }^{1}$ e a produção científica na área.

O direito à educação tem sido legitimado em diferentes documentos. No tocante à legislação, as Diretrizes Operacionais para a Educação Básica nas Escolas do Campo (Resolução CNE/CEB n 1/2002) já expressavam uma orientação para o desenvolvimento de um trabalho pedagógico articulado com a cultura, as tradições, os saberes e as identidades das populações do campo.

As Diretrizes apontam para uma flexibilização e adequação no calendário, nos agrupamentos etários e na organização de tempos, atividades e ambientes, respeitando as diferenças quanto à atividade econômica e à política de igualdade e sem prejuízo da qualidade do atendimento. Além disso, prevê oferta de materiais didáticos, brinquedos e outros equipamentos conforme a realidade da comunidade

\footnotetext{
${ }^{1}$ Em 2011/2012, em cooperação com o Ministério da Educação (MEC) e a Universidade Federal do Rio Grande do Sul (UFRGS), foi realizada a Pesquisa Nacional "Caracterização das práticas educativas com crianças de 0 a 6 anos residentes em áreas rurais".
} 
e as diversidades dos povos do campo, evidenciando o papel dessas populações na produção do conhecimento sobre o mundo.

As Diretrizes complementares, normas e princípios para o desenvolvimento de políticas públicas de atendimento da educação básica do campo (Resolução CNE/ CEB $n^{\circ} 2 / 2008$ ) regulamentam questões fundamentais para a educação infantil. Entre outras determinações, proíbem o agrupamento de crianças da educação infantil e crianças do ensino fundamental numa mesma turma.

As Diretrizes Curriculares Nacionais de Educação Infantil (DCNEI - 2009), em seu artigo $8^{\circ}$, parágrafo terceiro, o qual trata das propostas pedagógicas da educação infantil dos filhos de agricultores familiares, extrativistas, pescadores artesanais, ribeirinhos, assentados e acampados da reforma agrária, quilombolas, caiçaras e povos da floresta, destacam que é preciso:

I - reconhecer os modos próprios de vida no campo como fundamentais para a constituição da identidade das crianças moradoras em territórios rurais;

II - ter vinculação inerente à realidade dessas populações, suas culturas, tradições e identidades, assim como a práticas ambientalmente sustentáveis;

III - flexibilizar, se necessário, calendário, rotinas e atividades respeitando as diferenças quanto à atividade econômica dessas populações;

IV - valorizar e evidenciar os saberes e o papel dessas populações na produção de conhecimentos sobre o mundo e sobre o ambiente natural;

$\mathrm{V}$ - prever a oferta de brinquedos e equipamentos que respeitem as características ambientais e socioculturais da comunidade. (Brasil, CNE/CEB, Resolução 05/09, 2009a)

Portanto, é possível afirmar que o Brasil possui documentos orientadores da política educacional que precisam ser transformados em práticas cotidianas na vida de milhares de crianças que vivem no campo e têm direito a um espaço coletivo de educação. A questão crucial com a qual a sociedade e o Estado têm se deparado é como qualificar e ampliar a oferta de vagas para as crianças brasileiras, em especial quando observamos os dados censitários, os quais têm apontado que essa oferta na educação infantil para as crianças residentes no campo são extremamente desiguais.

Em recente relatório de pesquisa publicado pelo MEC, é destacado que:

As desigualdades apontadas entre as condições de vida das populações urbanas e rurais também ficam evidentes na análise do acesso à educação. Desta forma, ocorre uma "Sinergia negativa": as mais precárias condições de vida das crianças de até 6 anos residindo em área rural são reforçadas por seu menor acesso à educação, 
particularmente à creche, e, quando isto ocorre, a oferta educacional é de pior qualidade. (MEC, 2012, p.63)

Nessa perspectiva, a obrigatoriedade de matrícula na pré-escola foi entendida por muitos como sinônimo de universalização da oferta ou expansão da cobertura, mas, na verdade, foi um instrumento que ressignifica muito o conceito de educação infantil que temos construído historicamente. Por meio de nossa imersão na pesquisa, pretendemos apresentar alguns elementos para o debate, ultrapassando a emergência da implementação da oferta de educação infantil no/do campo.

Este artigo trata de uma parte de um projeto de pesquisa mais amplo ("Caracterização do atendimento às crianças de 0 a 6 anos residentes em áreas rurais no Estado do Rio Grande do Sul/Brasil"), realizado num contexto que contempla uma das diversidades dos sujeitos do campo, o qual é constituído por famílias de assentados da reforma agrária no assentamento Integração Gaúcha (IRGA), localizado na cidade de Eldorado do Sul/RS.

O local de estudo foi escolhido por três aspectos principais: possuir escola localizada em área rural com oferta de educação infantil para crianças de 0 a 6 anos; ser próximo de nosso local de origem (distante aproximadamente $20 \mathrm{~km}$ da cidade de Porto Alegre) e ter tido acolhimento da Secretaria Municipal de Educação da cidade para o desenvolvimento da pesquisa.

Este artigo busca problematizar a obrigatoriedade de matrícula na educação infantil no contexto do assentamento IRGA, por meio de entrevistas com famílias assentadas. Busca-se dar visibilidade à educação infantil do campo a partir das questões elencadas e dos achados da pesquisa.

O estudo configurou-se em uma pesquisa qualitativa de cunho etnográfico e contempla algumas características consideradas básicas por Bodgan e Biklen (1991), como o ambiente natural como fonte de dados, a coleta de dados predominantemente de forma descritiva, e o significado que as pessoas dão às coisas e às suas vidas como foco principal do pesquisador.

Os instrumentos metodológicos utilizados para realizar a pesquisa foram observações e entrevistas realizadas com famílias assentadas em suas residências, com agendamento prévio, seguindo um roteiro e com gravação mediante autorização assinada em Termo de Consentimento Livre e Esclarecido (TCLE); e elaboração de diários de campo logo após a conclusão das entrevistas. Nesses diários, buscamos descrever ações, apontar hipóteses e impressões iniciais no contexto das entrevistas. 


\section{A obrigatoriedade de matrícula no contexto do campo e do assentamento IRGA}

A Constituição da República Federativa do Brasil de 1988 estabelece "a educação como direito público subjetivo", sendo ela responsabilidade do poder público e da família. Para a educação das crianças de 0 a 6 anos, até o mês de abril de 2013, era opção da família matricular ou não seus filhos pequenos em instituições educativas. A opção se transformou em dever com a aprovação da Lei 12.796/13, que regulamenta a Emenda Constitucional 59/2009, legitimando que é dever dos pais ou responsáveis efetuar a matrícula das crianças na educação básica a partir dos quatro anos.

Assim, desde 2009, a matrícula de crianças a partir de quatro anos deixou de ser uma opção e/ou decisão da família, pois a nova legislação determina juridicamente essa idade para a matrícula na educação infantil. Em recente estudo a respeito dessa questão, Fernandes (2014) apresenta: A justificativa para a obrigatoriedade da pré-escola se embasou no argumento de
que esta pode influenciar positivamente no aproveitamento dos alunos nos anos
seguintes de escolaridade. Esse argumento do relator remeteu ao depoimento, em
audiências públicas, do ministro da educação, Fernando Haddad, em que relacionou
as deficiências de cobertura na pré-escola ao fracasso escolar: "É justamente a falta
de acesso à pré-escola que induz ao fracasso escolar nos anos iniciais do ensino
fundamental, à repetência elevada, ao analfabetismo de crianças de 8 a 14 anos." Além
disso, pontuou que há diferenças no ingresso à pré-escola de acordo com a renda da
população, concentrando-se a falta de acesso para as crianças de renda mais baixa.
(Fernandes, 2014, p. 47)

O estudo esclarecedor de Rosemberg (2009) sobre o tema da obrigatoriedade de matrícula na educação infantil destaca algumas questões cruciais para analisarmos a complexidade do tema: a) risco de cindir a educação infantil em duas partes (a préescola, obrigatória, que passa a um nível de prioridade, ressaltando sua importância educacional; e a creche, não obrigatória, que perde importância educacionalmente) (Rosemberg, 2009, p. 53); b) expectativa de que as crianças venham para o ensino fundamental socializadas no contato com o mundo letrado, ou alfabetizadas (Rosemberg, 2009, p. 21).

Outro aspecto destacado pela pesquisadora foi a pequena mobilização em torno do debate sobre matrícula/frequência obrigatória, em especial a ausência da voz das famílias de crianças de 4 e 5 anos nesse não debate sobre a obrigatoriedade da matrícula/frequência na pré-escola.

Ao analisar essas questões na perspectiva do campo, a cisão entre a creche e a préescola torna-se ainda mais grave, pois a oferta de vagas para as crianças de 0 a 3 
anos em creche no campo é praticamente inexistente. Assim, a lei da obrigatoriedade pode causar um efeito de estímulo apenas à oferta para a faixa etária obrigatória.

Os dados da Radiografia² de Educação Infantil no Rio Grande do Sul/2013, realizada pelo Tribunal de Contas do Estado, apontam:

[...] 17,9\% da população de 0 a 5 anos encontravam-se em situação de miséria e o maior índice de pobreza estava na zona rural, onde 30,67\% das crianças de 0 a 5 anos pertenciam a famílias com rendimento nominal mensal domiciliar per capita de até 140 reais. Na zona urbana, esse índice era de $15,89 \%$. Não bastasse o elevado contingente de crianças em situação de pobreza, há Municípios em que, mesmo a família dispondo de recursos para o custeio do ensino em instituição particular, o sistema público é a única forma de acesso à educação infantil. Isso ocorre, segundo o Censo Escolar de 2012, em 313 Municípios (63,1\% do Estado), onde inexiste uma única escola da rede particular, comunitária, confessional ou filantrópica como alternativa de ingresso. (TCE/RS, 2013, p. 3)

Portanto, se a falta de acesso à pré-escola devido à baixa renda foi justificativa para a implementação da Lei $12.796 / 13$, a população do campo, se tiver acesso, será potencialmente beneficiada em nosso estado. Todavia, tão importante e marcante quanto os "índices de situação de miséria" é o fato de que o sistema de ensino público é o único meio de acesso para a educação infantil em mais da metade dos municípios do Rio Grande do Sul. Isso demonstra o grande movimento que os municípios, responsáveis como entes federados na oferta de educação infantil, devem realizar para cumprir com a nova legislação.

Na Escola Municipal de Educação Infantil Flor da Terra, localizada dentro do assentamento IRGA, não existe fila de espera para a faixa etária de 4 e 5 anos, que abrange a etapa da pré-escola, segundo informação dada pela professora responsável ${ }^{3}$. No que tange a crianças de 0 a 3 anos, existe fila de espera de apenas duas crianças. A pequena fila de espera e a lista de 47 crianças matriculadas demonstram o quanto a oferta no contexto do campo, em especial, dentro do assentamento IRGA, induziu a busca da matrícula das crianças pelas famílias. Atualmente, a EMEI Flor da Terra atende prioritariamente a demanda das famílias assentadas. Nas vagas restantes, atende a crianças residentes na cidade ${ }^{4}$, realizando assim um deslocamento do urbano para o rural, inverso ao que é realizado em muitos municípios do país.

2 O Tribunal de Contas do RS desenvolve importante monitoramento de oferta de vagas na educação infantil no estado; no entanto, ainda não apresenta análise separada da oferta de vagas no que tange os espaços urbanos e rurais.

3 A organização das Instituições de Educação Infantil de Eldorado do Sul até pouco tempo era por meio de Unidade de Educação. Assim, para cada quatro escolas existia uma diretora e três professoras responsáveis.

4 As crianças que vêm da cidade são trazidas pelos pais ou por transporte privado (vans escolares pagas pelos pais), não sendo atendidas, portanto, por transporte público. 
Assim, o município de Eldorado do Sul, com a EMEI Flor da Terra, atende o que legitimam as Diretrizes Complementares, normas e princípios para o desenvolvimento de políticas de atendimento da educação básica no campo, Resolução $n^{\circ} 2$ de 28 de abril de 2008, em seu art. $3^{\circ}$ "A Educação Infantil e os anos iniciais do Ensino Fundamental serão sempre oferecidos nas próprias comunidades rurais, evitandose os processos de nucleação de escolas e de deslocamento das crianças". Ainda é possível inferir neste estudo que a oferta de matrículas dentro da própria comunidade evita a utilização do transporte escolar, que para a faixa etária de 0 a 6 anos ainda não possui nenhuma normatização de abrangência nacional.

O tema deste estudo é apresentado através das famílias assentadas no IRGA, que expressam suas perspectivas em relação à obrigatoriedade de matrícula na préescola.

\section{A pesquisa com famílias do campo}

O percurso entre Porto Alegre e o assentamento IRGA, percorrido no carro da universidade, era um tempo necessário para que ocorresse um afastamento da cidade e vivenciássemos uma imersão no campo - um espaço que nos permitia ter experiências muito diferentes das que habitualmente vivemos.

Nossa primeira imersão no assentamento foi acompanhada de uma líder do Movimento dos Trabalhadores Rurais Sem-Terra (MST) ${ }^{5}$, e tínhamos o objetivo de realizar um primeiro mapeamento das possíveis famílias que poderiam fazer parte do trabalho. É importante salientar que as famílias entrevistadas foram indicadas pela direção da escola, pelas lideranças do MST e pelas próprias famílias.

Essa estratégia vai ao encontro do que Victora, Knauth e Hassen (2000) apresentam a respeito da coleta de dados dentro de uma orientação etnográfica:

A coleta de dados depende do estabelecimento de uma relação entre o pesquisador e o pesquisado, sendo frequente uma técnica de obtenção de informantes conhecida como snowball, pela qual cada novo informante indica novas pessoas para participarem da pesquisa. (Victora; Knauth; Hassen, 2000, p. 38)

A partir do envolvimento com os informantes para este estudo, foram definidas para serem entrevistas as seguintes famílias: uma família com crianças de 0 a 3 anos atendidas em creche; uma família com crianças de 0 a 3 anos não atendidas em creche; uma família com crianças de 4 e 5 anos atendidas em pré-escola; uma família com crianças de 4 e 5 anos não atendidas em pré-escola, e duas famílias que

\footnotetext{
5 A imersão no assentamento ocorreu no mês de janeiro de 2014, e a acolhida e disponibilidade das lideranças do MST na comunidade foram fundamentais no processo de pesquisa.
} 
já foram atendidas em creche e pré-escola e lutaram pela conquista da educação infantil no assentamento.

\section{Dos instrumentos de pesquisa}

As entrevistas foram os principais instrumentos de pesquisa, mas destacamos a necessidade de complementaridade de outros recursos, como a observação e a escrita minuciosa dos diários de campo, que possibilitaram o enriquecimento do trabalho. Um aspecto fundamental foi o fato de que as entrevistas com as famílias sempre se realizaram em suas residências, o que possibilitou conhecer o lugar onde as crianças vivem e brincam. Além disso, conhecemos um pouco sobre o modo de funcionamento da casa, por vezes as características do local onde a família trabalha, a convivência familiar entre adultos e crianças, e a configuração familiar dos que residem na casa.

O contato inicial com as famílias entrevistadas foi via telefone, convidando todos da família para a entrevista. Observou-se que, na maioria das casas, a entrevista era dada pelas mulheres, como se a questão da educação das crianças fosse um assunto preferencialmente feminino. Mesmo quando o marido/companheiro estava em casa, ele observava, ouvia, mas encaminhava essas questões para sua companheira. Das seis entrevistas, em duas os maridos estiveram presentes durante toda a entrevista; mesmo assim, as primeiras a responder as questões sempre eram as mulheres.

Destacamos que nas seis famílias entrevistadas, embora as crianças estivessem por perto e a temática fosse do seu interesse, os adultos não permitiam que estas participassem. Pelo contrário, a todo o momento lhes era negada a palavra, dizendo que este não era um assunto para crianças. Albuquerque (2014, p. 7) apresenta que em alguns de seus estudos com famílias "[...] as crianças foram as principais protagonistas de minhas interações com outros integrantes da família, contando casos e manifestando seus pareceres." Isso demonstra as diferenças do entendimento dos modos de socialização das crianças conforme o contexto social em que estão inseridas.

Nosso objetivo principal era ouvir a perspectiva das famílias sobre a obrigatoriedade de matrícula para as crianças a partir de quatro anos, com base na Lei 12.796/13, destacando o $\operatorname{Art.} 6^{\circ}$, que legitima que "É dever dos pais ou responsáveis efetuar a matrícula das crianças na educação básica a partir dos 4 anos de idade". 


\section{O contexto da pesquisa}

As famílias do assentamento Integração Gaúcha (IRGA) 6 foram assentadas pelo Governo do Estado do Rio Grande do Sul e não pelo Instituto Nacional de Colonização e Reforma Agrária (INCRA), como muitos outros assentamentos do estado. Isso, segundo uma liderança do MST entrevistada, dificultou a vida das famílias, uma vez que não receberam nenhum recurso para moradia e nem subsídios por um ano para se manter, como era política do INCRA na época em que as famílias foram assentadas. Mesmo já assentadas, muitas famílias viveram por mais três ou quatro anos em barracas de lona, pois não tinham condições financeiras para construir suas moradias.

Em 1991, ano de início do assentamento IRGA, era exigido que as 68 famílias que constituíam o assentamento fossem associadas a uma cooperativa de produção. "A cooperação era uma exigência do governo gaúcho, responsável legal pelo assentamento, e, também uma forma de organização produtiva defendida pelo MST." (Campos, 2006, p. 11) Atualmente, a economia no assentamento gira em torno da produção de arroz, do leite e da agricultura familiar, e as famílias não são mais obrigadas a serem associadas à cooperativa.

A educação das crianças pequenas não foi uma demanda vivida logo no início do assentamento. Um estudo de Campos (2006) e o relato das famílias pesquisadas apontam que a maioria dos assentados no IRGA eram pessoas solteiras, em sua maioria homens e casais jovens. Desse modo, foi com o passar dos anos que as famílias foram se constituindo e as crianças foram nascendo.

Com a chegada das crianças, iniciou-se no assentamento a necessidade de um local onde as crianças pudessem ficar em segurança enquanto as famílias trabalhassem na horta ${ }^{7}$. As famílias entrevistadas destacam que inicialmente as crianças ficaram aos cuidados da creche organizada por elas ${ }^{8}$, "debaixo de uma árvore, mais tarde debaixo de uma varanda e depois de um 'galpãozinho' do movimento" (entrevista com pai de família 2, em 26 de maio de 2014).

No entanto, esse galpãozinho/escola era constituído por uma sala pequena, onde eram realizadas práticas de cuidado, alimentação e brincadeiras. Também nesse espaço, em separado, havia um banheiro e uma cozinha. Frequentaram nesse período 13 crianças maiores de 3 anos, que já não usavam mais fraldas, pois não

\footnotetext{
6 Segundo Campos (2006), o nome dado ao assentamento deve-se ao fato de ter se constituído em uma propriedade de autarquia do governo Estadual - IRGA (Instituto Rio-Grandense do Arroz). Como as famílias que constituem o assentamento eram oriundas de diversas regiões do Estado, as pessoas que moravam na cidade passaram a nominar os assentados como "os colonos do IRGA".

7 Horta é o nome dado pelas famílias ao espaço de trabalho na terra.

8 Nesse período inicial do assentamento, algumas mulheres ficavam com as crianças do grupo enquanto as outras acompanhavam seus companheiros na horta.
} 
havia trocador. Esses aspectos de falta de infraestrutura e condições fomentaram a necessidade um lugar adequado para a educação dos bem pequenos no assentamento, isto é, para os menores de 3 anos.

No ano de 2003, as famílias relataram algumas manifestações pelo centro da cidade, conduzidas pelas mulheres do assentamento. Em abril de 2004, foi organizada uma marcha reivindicando a construção de uma escola de educação infantil. As famílias apontaram que o prefeito passou a evitá-las e, assim, segundo Campos (2006, p.18), "[...] levando colchonetes, brinquedos e comidas 'acamparam' na recepção da prefeitura".

A autora aponta ainda:

Com o apoio da assessoria do MST, o fato repercutiu na imprensa de Porto Alegre. Por telefone as mães deram entrevistas denunciando a falta de creches no município e a violência com que estavam sendo tratadas na prefeitura. Quando a imprensa começou a procurar o prefeito para que explicasse a situação ele decidiu mudar completamente a atitude. Chamou as mulheres para uma audiência e autorizou a implantação do Centro de Educação Infantil no Assentamento. (Campos, 2006, p. 18)

Em setembro de 2006, foi inaugurada a EMEI Flor da Terra ${ }^{9}$ no assentamento IRGA, atendendo cerca de 20 crianças. Atualmente ${ }^{10}$, a escola atende 46 crianças, de 6 meses a 4 anos, divididas em berçário ( 6 crianças), maternal 1 (13 crianças) e maternal 2 (12 crianças). Ao lado da EMEI Flor da Terra existe a EMEF Almirante Tamandaré, que atende até $\mathrm{o} 4^{\circ}$ ano do ensino fundamental. Com a crescente procura de vagas na EMEI Flor da Terra, que atende não somente crianças do assentamento, mas também da cidade, foram deslocadas duas turmas de pré-escola para a EMEF Almirante Tamandaré, que fica ao lado da escola de educação infantil.

\section{As perspectivas das famílias sobre a obrigatoriedade de matrícula na pré-escola}

As características das famílias entrevistadas dentro do Assentamento Integração Gaúcha se mostraram heterogêneas. As famílias são oriundas de várias cidades do interior estado e todas passaram por migrações sucessivas até chegarem ao assentamento IRGA. Das famílias entrevistadas, todos os pais residem no assentamento desde seu início, 22 anos atrás. Somente dois dos casais entrevistados chegaram ao IRGA juntos. As outras quatro mulheres se integraram ao assentamento

\footnotetext{
9 O nome da escola era Arco-Íris, mas depois a comunidade optou pela troca do nome para Flor da Terra.

${ }^{10}$ Dados de 2013.
} 
a partir das relações conjugais, variando o tempo que lá residem entre 19 e 5 anos. No que se refere à escolarização, a maioria frequentou até o ensino fundamenta sem, no entanto, completá-lo, sendo que apenas uma mãe possui ensino médio completo, obtido por meio dos "provões" ${ }^{11}$ da Secretaria de Educação do Estado do Rio Grande do Sul. Quanto à escolarização dos filhos, somente em uma família foi informada a desistência dos estudos do filho no $6^{\circ}$ ano do ensino fundamental. Nas demais, todos os filhos estudam ou já concluíram o ensino médio.

A composição das famílias entrevistadas configura-se em pai, mãe e filhos biológicos. As famílias vivem do trabalho com horta agroecológica, plantio de arroz, venda de leite e agricultura de subsistência. Os produtos são vendidos em feiras, no Mercado Público de Porto Alegre e também são comercializados nas residências da área urbana na própria cidade e na merenda escolar do município. Uma família relatou que o excedente da sua produção é vendido na cooperativa.

As idades em que os filhos foram matriculados na escola são bastante distintas: a menor idade de matrícula foi aos 4 meses e apenas uma das seis famílias entrevistadas optou $^{12}$ por não matricular suas crianças na educação infantil.

A partir das entrevistas e do trabalho de campo, elencamos abaixo alguns eixos de análise que problematizam a questão da obrigatoriedade de matrícula na pré-escola.

\section{A legislação e a necessidade da educação infantil justificam a demanda}

O direito das mulheres e homens trabalhadores foi um dos fatores que justificaram a luta pela oferta de educação infantil. Nessa perspectiva, a não oferta de vagas para as crianças do assentamento estaria associada à rotina das mulheres do campo que, por desenvolverem trabalhos no entorno das casas, considerados no âmbito doméstico, não precisariam de creche e pré-escola.

Ao questionar a família 1, que tem crianças de 0 a 3 anos matriculadas na EMEI Flor da Terra, sobre o que pensa sobre a obrigatoriedade de matrícula, a resposta foi a seguinte:

[...] a creche é uma benção. É porque assim, o pequenininho, quando ele tinha 2 ou 3 mesinhos eu já levava ele pra horta, colocava ele na sombra, mas ele é muito branco, e é verão. No verão, sabe, mesmo na sombra ele ficava cheio de brotoeja,

11 Mantivemos "provões", pois foi assim que a mãe se referiu aos exames do Supletivo.

12 A partir do dia 16/01, quando realizamos a caminhada com a representante do MST e questionamos a família sobre o conhecimento da Lei $12.796 / 13$, a família procurou pela escola e, neste momento, encontra-se em fila de espera por vaga. 
ficava vermelhinho assim na sombra. Porque se eu não trabalhar a gente não vive né! (Entrevista, 17/06/2014)

Com a fala desta mãe ${ }^{13,}$ é possível aferir que a família agrega o direito das crianças à educação infantil ao direito da mãe ao trabalho. É importante ressaltar que todas as mulheres das famílias entrevistadas são trabalhadoras do campo, com ocupações específicas e importantes para o sustento da família. Essa condição também justifica que o direito à educação infantil é um direito social, que amplia a igualdade entre homens e mulheres também no campo. Para a família, a importância da educação infantil e o posicionamento sobre a obrigatoriedade de matrícula na pré-escola estão relacionados também à necessidade de que os filhos frequentem a escola para que a mãe possa trabalhar.

Um estudo realizado no contexto desse assentamento por Campos (Campos, 2006, p.15) destaca que no IRGA o direito à "[...] educação infantil produziu impactos em três aspectos: melhor aproveitamento do tempo; aumento da renda; e elevação da autoestima; a combinação desses impactos criou condições para uma maior autonomia das mulheres-mães." Bobbio (2006, p. 2), no que tange aos direitos, afirma que "o direito torna-se um dos principais indicadores do progresso histórico".

Outro aspecto constatado é que, na família 1, a opção em matricular os filhos na educação infantil aconteceu cada vez mais cedo com o passar dos anos e com a chegada dos filhos. Isso demonstra o reconhecimento por parte da família de que a escola é um lugar importante e seguro para seus filhos. Além disso, mostra que, desde que houve oferta de educação infantil naquele contexto, a demanda por vagas ocorreu cada vez mais cedo.

Albuquerque e Votto (2012, p. 277) apontam que, para as famílias com as quais realizaram seus estudos, a frequência das crianças à escola poderia afastá-las da exposição a "[...] riscos como insetos, cobras, contaminação com agrotóxicos e etc. Estas famílias revelam que as crianças ficariam mais protegidas e cuidadas se permanecerem na escola, o que traria também aos pais mais tranquilidade para realizarem seu trabalho". Isso corrobora, portanto, o que apresenta a mãe entrevistada:

Coloquei ele na escola porque no ano que vem é obrigatório [...] e é bom porque agora ele já aprende alguma coisinha e vai mais preparado para a escola depois. [...] fiquei sabendo pela TV da lei, daí corri lá e logo matriculei ele né. (Entrevista, 19/03/2014)

Além da necessidade de um espaço seguro para deixar os filhos, as famílias entrevistadas neste estudo destacam que a regulamentação da legislação induziu a busca pela matrícula.

${ }^{13}$ Todas as entrevistas foram transcritas. 


\section{Intervenção do Estado numa decisão da família}

Outro elemento encontrado na pesquisa se refere à intervenção do Estado numa decisão da família. O pai da família entrevistada 2 se posiciona da seguinte forma sobre o tema:

Senão daqui uns anos vão dizer: "Ôh! Tu nasceu, vai ter que ir pra escola!" Tem que levar estudar, é obrigado. Daí não tem aquele incentivo de tu ir lá levar porque tu quer. Não os outros de decidir por ti, se tu quiser levar com 2, 3 , 4 anos tu leva, voluntariamente, não ser uma lei que é obrigado né?" (Entrevista, 26/05/2014)

Rosemberg (2009) coloca em debate a pertinência de o Estado forçar a família a matricular seu filho ou filha de 4 e 5 anos em pré-escola. Historicamente os movimentos sociais que lutam pelo direito à educação infantil reivindicavam a obrigatoriedade de oferta por parte do Estado, mas a matrícula como uma opção da família. A nova legislação impõe a matrícula. No contexto da pesquisa, o pai entrevistado considera uma imposição do Estado, o que o faz sentir-se invadido em relação a seu direito de decisão sobre o que acredita ser melhor para seus filhos.

$\mathrm{Na}$ família 2, que tem uma filha de 0 a 3 anos não matriculada na escola de educação infantil, a mãe expressa sua perspectiva nesta direção:

Não gosto muito dessas coisas de regras, que tu tem que fazer [...] Eu acho que tu deve escolher se tu quer ou não. Eu comecei ir pro colégio com 7 anos e eu acho que aprendi o que tinha que aprender. Eu acho que não deveria ser obrigatório, tu tem que ter o direito de escolher como vai ser a vida do teu filho. É tudo obrigado. (Entrevista, 26/05/2014)

Ter opção e ter direito são dimensões importantes à cidadania para quem vive num estado democrático. Historicamente a educação infantil é uma questão do âmbito privado das famílias. A Constituição Federal de 1988 estabelecia o direito à educação infantil, mas não uma obrigação de matrícula para as famílias. A Lei 12.796/13 vem, portanto, ampliar a garantia do direito estabelecido na Constituição. Pode-se pensar que a obrigatoriedade é uma intervenção do Estado em favor da criança, legitimando seu direito à educação.

A família entrevistada 4 que, por opção, tem filhas de 4 e 5 anos não matriculadas na educação infantil, apresenta o seguinte sobre a obrigatoriedade de matrícula na pré-escola:

Não sei, até porque a gente fica sozinho dentro de casa. Tendo eles aí a gente fica toda hora conversando, te pede uma coisa, te pede outra, daí tu atende elas. E, elas tando na creche, tu fica perdida dentro de casa, a casa vazia. E isso que é problema também. (Entrevista, 25/03/2014) 
Assim, o direito das filhas de frequentarem a escola não é garantido, pois os adultos da família apresentam a sua necessidade de companhia. Essa questão leva a outra análise: a "cultura adultocêntrica" (Albuquerque, 2009) no que se refere ao direito das crianças. Nessa família, a mãe apresenta argumentos que legitimam a necessidade do adulto e não o ponto de vista da criança e suas necessidades.

Resta saber, então, como o Estado vai intervir se o direito da criança for negado por decisão da família de não matricular na pré-escola. Essa família, por motivos de âmbito privado, será acionada judicialmente? Será utilizada a mesma legislação do ensino fundamental em que os pais que não zelam pela matrícula/frequência das crianças são imputados pelo crime de responsabilidade do art. 246 do Código Penal?

Essas são perguntas ainda indefinidas que somente o processo histórico vivenciado irá responder por meio da mediação entre a legislação e o cotidiano das crianças e suas famílias.

\section{As concepções sobre educação infantil e sua importância para as famílias entrevistadas}

Foram recorrentes, nas entrevistas com as famílias, falas a respeito da importância da educação infantil para as crianças brincarem e socializarem. No entanto, falas que remetem a uma interpretação de que a educação infantil serve para estudar, preparar para a escola, tendo como referência o ensino fundamental, foram expressas por duas das seis famílias entrevistadas.

A família 4, que possui filhas de 4 e 5 anos não matriculadas na educação infantil, apresenta que é:

Pesado para eles, porque não têm cabeça pra saber o que eles querem. Mais é pra brincar né? Pra fazer folia, porque eles não se interessam de dizer ou pegar um caderno pra estudar, eles querem brincar. Só que se é a lei a gente tem que respeitar né? Não adianta. (Entrevista, 25/03/2014)

A concepção das interações e brincadeiras como eixo das práticas pedagógicas da educação infantil é apresentada nas Diretrizes Curriculares Nacionais de Educação Infantil (DCNEl/2009). Esta se articula com a perspectiva dessa mãe, a qual entende que, nas idades de 4 e 5 anos, ir para a escola significa brincar e fazer folia.

No manual de Orientação Pedagógica-Módulo I, Brincadeira e Interações nas Diretrizes Curriculares para a Educação Infantil apresentam o entendimento de que o brincar: 
[...] é atividade principal da criança. Brincar é repetir e recriar ações prazerosas, expressar situações imaginárias, criativas, compartilhar brincadeiras com outras pessoas, expressar sua individualidade e sua identidade, explorar a natureza, os objetos, comunicar-se e participar da cultura lúdica para compreender seu universo. Ainda, que o brincar possa ser considerado um ato inerente à criança, exige um conhecimento, um repertório que ela precisa aprender. (Brasil, 2012, p. 7)

Ao mesmo tempo, é possível observar que, nas experiências dessa mãe, a escola se apresenta como um lugar "pesado e que precisa de caderno para estudar". Essas duas perspectivas se contradizem quando reconhecemos a especificidade da educação infantil.

A mãe da família 6 argumenta que "[...] é bom porque agora ele já aprende alguma coisinha e vai mais preparado para a escola depois". O Parecer do Conselho Nacional de Educação (CNE/CEB n 20/2009b) a respeito disso especifica que:

[...] têm se mostrado prioritárias as discussões sobre como orientar o trabalho junto às crianças de até 3 anos em creche e como garantir práticas junto às crianças de 4 e 5 anos que se articulem, mas não antecipem as práticas do Ensino Fundamental. (Brasil, 2009b, on-line)

As concepções previstas nas Orientações Curriculares para a Educação Infantil do Campo (2010) apresentam que é necessário:

Uma educação infantil que valorize suas experiências, seus modos de vida, sua cultura, suas histórias e suas famílias, que respeite os tempos do campo, os modos de convivência, as produções locais. Uma educação infantil que permita que a criança conheça os modos como sua comunidade nomeia o mundo, festeja, canta, dança, conta histórias, produz e prepara seus alimentos. Creches e pré-escolas com a cara do campo, mas também com o corpo e a alma do campo, com a organização dos tempos, atividades e espaços organicamente vinculados aos saberes de seus povos. (Brasil, 2010, p. 2)

Ter o direito à educação infantil no campo amplia as possibilidades de experiências coletivas para as crianças que vivem nesses ambientes. Devido às dificuldades relacionadas à distância e à ocupação dos pais, a escola de educação infantil, por vezes, é o único local de encontro com seus pares e única possibilidade de socialização a que as crianças que lá residem têm acesso.

Nesta pesquisa, é possível aferir que, para todas as famílias entrevistadas, a escola de educação infantil no assentamento é muito importante, tanto para o desenvolvimento das crianças quanto para que os pais possam trabalhar com tranquilidade. No entanto, a legislação que obriga a matrícula deve também legitimar uma oferta de qualidade.

A preocupação com a qualidade de oferta foi apresentada nas entrevistas, com 
maior ênfase, pelas famílias que se engajaram na luta pela EMEI Flor da Terra. Isso evidencia que apenas o acesso à escola não é suficiente, mas que este venha implicado em qualidade de espaço, de materiais e de professores.

$\mathrm{Na}$ família 5, ao ser questionada sobre a obrigatoriedade de matrícula, a mãe argumenta:

[...] no começo me assustei com a ideia né. Daqui a pouco as mães vão ter que parir os filhos dentro da escola. Eu achei assim, muito cedo, 4 e 5 aninhos. Por mais que eles vão lá pra brincar, eles vão pra ter uma recreação, eu acho que isso também é importante pra eles assim [...] mas desde que tenha estrutura né? Porque não adianta também a gente pegar e levar nossos filhos lá e não ter aquela atenção toda com atividades realmente pra idade deles. Que não adianta nos fazer um acúmulo de criança em sala de aula e deixar ali meio sem ter mais professores. Acho que tem que ter mais professores, mais espaços pra eles também né [...] (Entrevista, 14/02/2014)

O pai da família 6, ao ser questionado sobre a obrigatoriedade, lança uma pergunta que também está implicada na questão da qualidade: "Essa lei mais é pros pais? Bota as crianças? Não tem que ter a lei pra que o município tenha estrutura pra isso?"

Todas as dimensões qualificam a escola de educação infantil como um espaço de vida coletiva, de troca de experiências e aprendizagens entre crianças e adultos, mas é preciso ter condições e infraestrutura.

\section{Considerações finais}

A heterogeneidade encontrada nas falas das famílias do assentamento IRGA a respeito do tema reforça a necessidade de estudos sobre a real demanda das populações do campo em relação à matrícula de seus filhos e às condições de oferta para o cumprimento da nova legislação.

Consideramos que o poder público, com a Lei 12.796/13, assume um grande compromisso com o campo brasileiro e, especialmente, com as crianças que lá residem. Surge um grande desafio: "minimizar as diferenças da falta de acesso para as crianças com renda mais baixa". Porém, é necessária para isso uma mobilização da Secretaria de Educação dos municípios - uma vez que estes são os responsáveis pela educação infantil - em relação ao que realmente é adequado nas práticas educativas na pré-escola.

Salientamos a necessidade de um cuidado especial para que as vivências das crianças na escola do campo não sejam reproduções das experiências realizadas em espaço urbano. Agregar a comunidade e as famílias nessa reflexão pode ser uma excelente iniciativa. 
A "intervenção" com a Lei 12.796/13 causou sentimento de invasão aos direitos das famílias pesquisadas. Consideramos que é necessário ampliar o debate sobre as formas de ascensão ao direito, em especial quando o direito envolve crianças.

A possibilidade de oferta de educação infantil no campo é uma forma de integração das políticas para os homens e mulheres trabalhadores do campo e para as crianças. Assim, essa oferta precisa estar aliada aos valores comunitários, reconhecendo as especificidades dos sujeitos do campo.

Na década em que aprovamos o Plano Nacional de Educação (2014-2024), em que almejamos a consolidação de uma concepção de direito à educação, desejamos que a educação infantil seja reconhecida como uma política educacional e social. Assim, a oferta de qualidade dessa etapa da educação básica no campo possibilitará uma maior igualdade entre homens e mulheres no plano do trabalho e da vida familiar; para as crianças, oferecerá a oportunidade de viver e aprender de forma coletiva com seus pares.

\section{Referências}

ALBUQUERQUE, Simone Santos de. Crianças em seus contextos familiares: implicações e desafios da pesquisa. No prelo 2014.

AlBuQUERQUE, Simone Santos de. Para além do "Isto" ou "Aquilo": Os sentidos da educação das crianças pequenas a partir das lógicas de seus contextos familiares. 2009. (368f). Tese (Doutorado em Educação). Programa de Pós-graduação em Educação da Faculdade de Educação da Universidade Federal do Rio Grande do Sul/UFRGS, 2009.

ALBUQUERQUE, Simone Santos de; FERNANDES, Cinthia Votto. Demanda por Educação Infantil: apontamentos a partir dos contextos familiares na Região Sul do Brasil. In: BARBOSA, Maria Carmen Silveira et al. Oferta e demanda de Educação Infantil no campo. Porto Alegre. Evangraf, 2012. P. 255-289.

BOBBIO, Norberto. A era dos direitos. Tradução de Carlos Coutinho. Rio de Janeiro: Campus/Elsevier. 2004.

BOGDAN, Robert C.; BIKLEN, Sari K. Investigação qualitativa em educação: Uma introdução à teoria dos métodos. 2.ed. Porto: Porto Editora, 1991. 
BOITO, Crisliane. "Ôh! Tu nasceu! Vai ter que ir pra escola!": Perspectivas de famílias do campo sobre obrigatoriedade de matrícula na Educação Infantil. 2014. (45 f.) Trabalho de Conclusão do Curso de Licenciatura em Pedagogia- Faculdade de Educação, Universidade Federal do Rio Grande do Sul/UFRGS. Porto Alegre, 2014.

BRASIL. (Constituição de 1988). Constituição da República Federativa do Brasil. Brasília: Senado Federal, 1988. Disponível em: http://www.planalto.gov.br/ ccivil_03/Constituicao/Constituicao.htm. Acesso em: 10/06/2015.

. Congresso Nacional. Lei n 9.394, de 20 de dezembro de 1996. Estabelece as Diretrizes e Bases da Educação Nacional. Diário Oficial [da República Federativa do Brasil]. Brasília: 1996. Disponível em: <http://www.planalto.gov.br/ccivil_03/leis/ 19394.htm>. Acesso em: 05/07/2014.

Ministério da Educação. Secretaria de Educação Básica. Parâmetros Nacionais de Qualidade para Educação Infantil. Brasília: MEC/SEB, 2006. Disponível em: http://portal.mec.gov.br/seb/arquivos/pdf/Educinf/eduinfparqualvol1.pdf. Acesso em 14.06.2015.

. Ministério da Educação. Conselho Nacional de Educação. Resolução CNE/ $\mathrm{CEB}, \mathrm{n}^{\circ} 2$, de 28 de abril de 2008. Estabelece diretrizes complementares, normas e princípios para o desenvolvimento de políticas públicas de atendimento da Educação Básica do Campo. Brasília: CNE, 2008. Disponível em: <http://portal.mec.gov.br/ arquivos/pdf/resolucao_2.pdf>. Acesso em: 05/07/2014.

. Emenda Constitucional $n^{\circ}$ 59, de 11 de novembro de 2009. Diário Oficial da União, Brasília, 2009. Disponível em: http://www.planalto.gov.br/ccivil_03/ constituicao/Emendas/Emc/emc59.htm. Acesso em 14/06/2015.

Ministério da Educação. Conselho Nacional de Educação. Resolução CNE/ CEB, $n^{\circ}$ 5, de 17 de dezembro de 2009a. Fixa as Diretrizes Curriculares Nacionais para a Educação Infantil. Brasília: CNE, 2009. Disponível em: <http://www.seduc. ro.gov.br/portal/legislacao/RESCNE005_2009.pdf>. Acesso em: 05/07/2014

Ministério da Educação. Conselho Nacional de Educação. Parecer CNE/CEB $n^{\circ} 20$, de 11 de novembro de 2009b. Diretrizes Curriculares Nacionais para a Educação Infantil. Disponível em: <http://portal.mec.gov.br/index.php?option=com_ content\&id=12745:ceb-2009>. Acesso em: 05/07/2014

Ministério da Educação. Secretaria da Educação Básica. Brincadeira e interações nas Diretrizes Curriculares para a Educação Infantil: manual de orientação pedagógica: módulo I/Brasil. Ministério da Educação. MEC/SEB, 2012.

Congresso Nacional. Lei $n^{\circ} 12.796$, de 04 de abril de 2013. Altera a Lei $n^{\circ}$ 
9.394, de 20 de dezembro de 1996, que estabelece as diretrizes e bases da educação nacional, para dispor sobre a formação dos profissionais da educação e dar outras providências. Diário Oficial [da República Federativa do Brasil]. Brasília: 2013. Disponível em: <http://www.planalto.gov.br/ccivil_03/_ato2011-2014/2013/lei/ |12796.htm>. Acesso em: 05/07/2014.

CAMPOS, Christiane Senhorinha Soares. Educação infantil pública: uma ferramenta para ampliar a autonomia de mulheres-mães em áreas de reforma agrária. Eldorado do Sul. 2006. Não publicado.

FERNANDES, Cinthia Votto. Entre a transição para o Ensino Fundamental e a obrigatoriedade de frequência: significados que tecem a identidade da pré-escola. 2014 (248f.). Tese (Doutorado em Educação) - Programa de Pós-Graduação, Faculdade de Educação, Universidade Federal do Rio Grande do Sul. 2014.

MEC/COEDI. Relatório 2. Condições educacionais de crianças de 0 a 6 anos residindo em área rural a partir de dados secundários. Pesquisa Nacional Caracterização das Práticas Educativas com crianças de 0 a 6 anos residentes em áreas rurais. Brasília, MEC/CODI-UFRGS, 2012.

RIO GRANDE DO SUL. Tribunal de Contas do Estado. Radiografia da Educação Infantil no RS: Análise do desempenho 2013. Disponivel em: <http://www1.tce. rs.gov.br/portal/page/portal/noticias_internet/Relatorios/Radiografia_Educacao_ Infantil2013.pdf>. Acesso em: 06/07/2014.

ROSEMBERG, Fúlvia. A educação pré-escolar obrigatória: versão preliminar. 2009. P.56 Disponível em: http://educarparaaigualdadeetnicoracial.ning.com/forum/ attachment/download?id=3547189\%3AUploadedFile\%3A2323. Acesso em 10/06/2015.

SILVA, Ana Paula Soares da; PASUCH, Jaqueline. Orientações Curriculares para a Educação Infantil do Campo. In: Anais do I Seminário Nacional: Currículo em Movimento - Perspectivas Atuais. Belo Horizonte, novembro de 2010. Disponível em: $\quad<$ http://portal.mec.gov.br/index.php?Itemid=\&gid=6675\&option=com_ docman\&task=doc_download. Acesso em: 16/09/2012.

SILVA, Ana Paula Soares da; PASUCH, Jaqueline; SILVA, Juliana Bezzon da. Educação Infantil do Campo. São Paulo: Cortez, 2012.

VICTORA, Ceres Gomes; KNAUTH, Daniela Riva; HASSEN, Maria de Nazareth Agra. Pesquisa qualitativa em saúde: uma introdução ao tema. Porto Alegre: Tomo Editorial, 2000. 
Recebido em maio de 2015

Aprovado outubro de 2015

Simone Santos de Albuquerque é doutora em Educação pela Universidade Federal do Rio Grande do Sul (UFRGS) e professora da Faculdade de Educação da UFRGS, atuando no Departamento de Estudos Especializados (DEE) na área de Educação Infantil. Pesquisadora e vice-líder do Grupo de estudos em Educação Infantil e Infâncias (GEIN/UFRGS) na linha de pesquisa Políticas e Pedagogias da Educação Infantil. Pesquisadora do Núcleo de Estudo em Educação das Infâncias (NEPE/FURG).

E-mail: sialbuq@gmail.com

Crisliane Boito é pedagoga pela Universidade Federal do Rio Grande do Sul (UFRGS). Pesquisadora do Grupo de Grupo de Estudos em Educação Infantil - GEIN/UFRGS.

E-mail: crisliane.boito@gmail.com 